\title{
IMPLEMENTASI METODE OUTDOOR LEARNING TERHADAP COMPLEX PROBLEM SOLVING SKILLS PADA MATA PELAJARAN IPA SISWA KELAS V SDN 56 PEKANBARU
}

\author{
Riyanda Maisya, Neni Hermita*, Eddy Noviana, Mahmud Alpusari \\ Program Studi Pendidikan Guru Sekolah Dasar, Fakultas Keguruan IImu \\ Pendidikan, Universitas Riau \\ neni.hermita@lecturer.unri.ac.id
}

\section{ABSTRACT}

The purpose of this study was conducted to determine differences in students' complex problem solving skills before and after the application of outdoor learning methods. This study uses a Pre-Experimental Design research method using one group pretest posttest design with a total of 19 students. The results of the study stated that in the pretest has an average value of 49.05 with the highest value of 76 and the lowest value of 11. After being given treatment using outdoor learning methods, the results of complex problem solving skills of students increased significantly namely having an average value of 60 with the highest value of 83 and the lowest value is 16 . The average increase in the pretest and posttest is 0.21 with low interpretation. Therefore it can be concluded that there are differences in complex problem solving skills of students of class V SDN 56 Pekanbaru.

Kata Kunci : Outdoor Learning; Complex Problem Solving Skills

\section{PENDAHULUAN}

Seiring dengan perkembangan zaman, siswa selalu dituntut untuk lebih giat dalam belajar. Mereka semakin kritis, mampu berpikir jauh kedepan, dan lebih agresif. Apalagi kini para pakar meramal bahwa ditahun 2020 dunia akan memasuki era industri 4.0. Di era tersebut akan banyak bermunculan robot canggih, superkomputer, kendaraan otonom, 3D printing, serta pengoptimasian fungsi otak manusia dengan editing genetik dan perkembangan neuroteknologi. Sehingga

R. Maisya, N. Hermita, E. Noviana, \& M. Alpusari, Implementasi Metode Outdoor Learning terhadap Complex Problem Solving Skills pada Mata Pelajaran IPA Siswa Kelas v sdn 56 
revolusi ini mau tak mau menuntut kita untuk terus mengembangkan skill yang dapat bermanfaat untuk masa depan. Oleh karena itu, pendidikan di Indonesia harus bisa menghadapi revolusi industri 4.0 ini dengan cara menciptakan pembelajaran yang menarik bagi siswa pun bukan hanya sekedar menyenangkan, namun memiliki berbagai kelebihan yang mampu memberikan motivasi tersendiri untuk terus mengembangkan minat dan rasa ingin tahu siswa dalam menguasai pengetahuan dan keterampilan baru.

Ilmu Pengetahuan Alam (IPA) merupakan pengetahuan tentang fakta dan hukum-hukum yang didasarkan atas pengamatan dan disusun dalam suatu sistem yang teratur. IImu Pengetahuan Alam (IPA) berhubungan dengan cara mencari tahu tentang alam secara sistematis.

Dalam proses pembelajaran IPA ini, guru yang aktif dan siswa pasif. Kegiatan belajar siswa sangat tergantung pada guru dan kebanyakan dari proses pembelajaran ini hanya sedikit siswa yang mampu mencapai ketuntasan. Dalam menyelesaikan permasalahan cukup memilih penyelesaian yang sesuai dengan permasalahan yang diberikan. Tidak adanya kerjasama antara sesama siswa sehingga siswa kurang aktif dalam pembelajaran dan tidak dapat membuat keputusan secara berdiskusi dalam menyelesaikan suatu masalah. Pendidikan IPA diharapkan dapat menjadi wahana bagi siswa untuk mempelajari diri sendiri dan alam sekitar.

Outdoor learning menurut Komarudin (dalam Husamah, 2013) merupakan aktivitas luar sekolah yang berisi kegiatan di luar kelas/sekolah dan di alam bebas lainnya, seperti bermain di lingkungan sekolah, taman, perkampungan pertanian/nelayan, berkemah, dan kegiatan yang bersifat kepetualangan, serta pengembangan aspek pengetahuan yang relevan. Outdoor learning dikatakan mampu memberikan pengalaman yang berkesan karena dalam pembelajaran tersebut siswa dapat memaksimalkan penggunaan indra yang mereka miliki demi mengembangkan rasa ingin tahu dan mencapai tujuan pembelajaran yang diinginkan secara langsung di alam terbuka sehingga pembelajaran bersifat

R. Maisya, N. Hermita, E. Noviana, \& M. Alpusari, Implementasi Metode Outdoor Learning terhadap Complex Problem Solving Skills pada Mata Pelajaran IPA Siswa Kelas v sdn 56 
konkret. Pendidikan luar kelas tidak sekedar memindahkan pelajaran ke luar kelas, tetapi dilakukan dengan mengajak siswa menyatu dengan alam dan melakukan beberapa aktivitas yang mengarah pada terwujudnya perubahan perilaku siswa terhadap lingkungan.

Pembelajaran yang berlangsung di kelas membuat siswa merasa bosan dan tidak memiliki motivasi untuk belajar. Pada kenyataannya materi pembelajaran yang cenderung abstrak disajikan secara text book sehingga siswa kesulitan untuk memahami materi yang disajikan. Rutinitas siswa yang terus dilakukan didalam ruangan secara terus menerus dari pagi hingga siang akan memberikan efek buruk bagi mereka, seperti tidak memiliki ruang gerak untuk dapat mengembangkan rasa ingin tahunya dan bereksplorasi seluas-luasnya sehingga menyebabkan mereka kurang dapat belajar dengan maksimal. Kondisi tersebut jelas akan menimbulkan kejenuhan, baik bagi siswa maupun guru itu sendiri.

Di sekolah dasar pembelajaran IPA merupakan proses memberikan pengalaman kepada siswa tentang fenomena atau gejala alam yang dapat dilakukan secara langsung di alam itu sendiri. Untuk anak sekolah dasar seyogyanya materi pembelajaran IPA diawali dengan yang konkret atau kasat mata karena mengingat tingkat kemampuan anak yang masih tergolong operasional konkret. Metode outdoor learning ini cocok untuk diterapkan pada mata pelajaran IPA karena outdoor learning dapat merangsang siswa untuk dapat tertarik dalam belajar karena belajar di luar kelas dapat membuat pikiran lebih jernih, pembelajaran terasa menyenangkan, belajar lebih riil. Outdoor learning juga mampu merangsang siswa untuk lebih kreatif dalam mencari alternatif pemecahan masalah, karena skill yang dibutuhkan untuk menghadapi revolusi industri 4.0 salah satunya adalah complex problem solving yang artinya siswa memiliki kemampuan untuk menyelesaikan masalah komplek serta menemukan pelajaran yang dapat dipelajari untuk menyelesaikan masalah.

Outdoor learning memiliki tujuan utama, yaitu sebagai berikut : (1) Dari segi kreativitas guru yang merangsang kreativitas siswa, secara tidak langsung, outdoor

R. Maisya, N. Hermita, E. Noviana, \& M. Alpusari, Implementasi Metode Outdoor Learning terhadap Complex Problem Solving Skills pada Mata Pelajaran IPA Siswa Kelas v sdn 56 
learning membuat guru untuk lebih kreatif dalam menyusun skenario pembelajaran; (2) Dari segi keaktifan siswa, outdoor learning mampu memberikan kesempatan seluas-luasnya kepada siswa untuk aktif bekerja dan bereksplorasi guna mencapai kompetensi yang menjadi tujuan pembelajaran; dan (3) Outdoor learning dapat menyeimbangkan dan memaksimalkan pencapaian tiga ranah sekaligus, yaitu, pengetahuan, sikap, dan keterampilan.

Secara rinci, kelebihan outdoor learning dapat dijelaskan sebagai berikut : (1) siswa lebih termotivasi dan aktif untuk belajar; (2) belajar di lingkungan yang tidak biasa bagi siswa membuat mereka mendapatkan pengalaman baru sehingga termotivasi untuk belajar; (3) lebih mengembangkan kreativitas guru; (4) melatih siswa bersosialisasi secara langsung; (5) paket lengkap pencapaian pengetahuan, sikap, dan keterampilan; dan (6) pembelajaran lebih dapat mengembangkan nilainilai karakter.

Namun demikian, Menurut Sudjana dan Rivai (dalam Husamah, 2013), beberapa kelemahan dan kekurangan yang sering terjadi dalam pelaksanaannya misalnya : (1) kegiatan belajar kurang dipersiapkan sebelumnya yang menyebabkan pada waktu siswa dibawa ke tujuan tidak melakukan kegiatan belajar yang diharapkan, sehingga ada kesan main-main. Kelemahan ini bisa diatasi dengan persiapan yang matang sebelum kegiatan dilaksanakan. Misalnya menentukan tujuan belajar yang diharapkan dimiliki siswa, menentukan apa yang harus dipelajarinya, berapa lama dipelajari, cara memperoleh informasi, mencatat hasil yang diperoleh, dan lain-lain; (2) ada kesan guru dan siswa bahwa kegiatan mempelajari lingkungan memerlukan waktu yang cukup lama, sehingga menghabiskan waktu untuk belajar di kelas. Kesan ini keliru sebab misalnya kunjungan ke kebun sekolah untuk mempelajari keadaan tanah, jenis tumbuhan, dan lain-lain cukup dilakukan beberapa menit, selanjutnya kembali ke kelas untuk membahas lebih lanjut apa yang telah dipelajari; dan (3) sempitnya pandangan guru bahwa kegiatan belajar hanya terjadi di dalam kelas. la lupa bahwa tugas belajar siswa dapat dilakukan di luar jam kelas atau pelajaran baik secara individual 
maupun kelompok dan satu di antaranya dapat dilakukan dengan mempelajari keadaan lingkungannya.

Menurut Vera (2012) langkah-langkah penerapan metode Outdoor Study yaitu:

\section{a. Tahap Perencanaan}

Sebelum melaksanakan kegiatan Outdoor Study, perencanaan harus dilakukan agar hasilnya maksimal, dengan cara:

1) Guru menetapkan tujuan pembelajaran berkaitan dengan kegiatan Outdoor Study yang dilakukan.

2) Guru menetapkan objek yang akan diamati.

3) Menentukan alat yang dibutuhkan.

4) Guru membuat instrumen yang diperlukan dalam kegiatan Outdoor Study.

5) Guru memperkirakan resiko yang bisa muncul keltika pelaksanaan pembelajaran sehingga memunculkan solusi dalam menyikapi resiko tersebut dan menghindari hal-hal yang tidak diinginkan.

6) Guru memastikan kegiatan Outdoor Study membutuhkan perijinan atau tidak. Hal ini dilakukan agar tidak ada pihak yang merasa keberatan.

b. Tahap Pelaksanaan

1) Siswa dan guru secara langsung menuju ke tempat yang telah ditentukan.

2) Siswa melakukan pengamatan dan dibimbing oleh guru yang mendampingi. Pengamatan disesuaikan dengan teori yang dipelajari. Dalam Outdoor Study, siswa disarankan untuk memegang buku pelajaran yang berkaitan dengan hal yang mereka amati.

3) Ketika melakukan pengamatan, sesekali guru menerangkan tentang sesuatu yang diamati oleh siswa sehingga mereka makin mudah memahami.

4) Sesekali guru dan siswa bertanya jawab.

5) Siswa mencatat semua hasil pengamatan. Setelah pengamatan dilakukan, siswa harus menyusunnya ke dalam bentuk laporan yang diserahkan kepada guru, kemudian laporan itu dibahas bersama guru.

R. Maisya, N. Hermita, E. Noviana, \& M. Alpusari, Implementasi Metode Outdoor Learning terhadap Complex Problem Solving Skills pada Mata Pelajaran IPA Siswa Kelas v sdn 56 
Istilah Complex problem solving sudah ada sejak tahun 1978. Patton menekankan cara pemecahan masalah Complex problem solving sebagai " a way of breaking down the complexity of the real world' artinya sebuah metode untuk memperjelas sesuatu hal yang sangat kompleks di kehidupan nyata. Complex problem solving merupakan kemampuan untuk menyelesaikan masalah yang kompleks dimulai dari melakukan identifikasi, menentukan elemen utama dari suatu masalah, melihat berbagai kemungkinan sebagai solusi, melakukan aksi/tindakan untuk menyelesaikan masalah, serta menemukan pelajaran yang dapat dipelajari untuk menyelesaikan masalah. Indikator yang dapat diukur dari complex problem solving skills melalui:

\section{Mendefinisikan masalah}

Kunci dari mendefinisikan masalah yang baik adalah memastikan bahwa siswa menangani masalah yang sebenarnya. Mendefinisikan masalah adalah bagian yang sangat penting untuk memahami situasi kompleks di mana masalah terjadi, sehingga dapat menentukan dengan tepat apa masalahnya.

2. Mencari alternatif

Setelah masalah sudah ditetapkan dengan tepat, maka selanjutnya ialah mencari alternatif yang bisa dilakukan dalam pemecahan masalah yang kompleks tersebut.

3. Mengevaluasi dan memilih alternatif

Setelah mencari alternatif yang bisa dilakukan, maka langkah selanjutnya ialah mengevaluasi atau memilah serta memilih alternatif apa yang sekiranya bisa dilakukan atau yang sangat tepat untuk diterapkan.

4. Menerapkan solusi

Menerapkan solusi yang dimaksud adalah setelah permasalahan sudah ditentukan dengan tepat, alternatif sudah dicari, kemudian alternatif tersebut di evaluasi atau dipilah serta dipilih, maka langkah selanjutnya ialah menerapkan solusi yang tepat agar masalah yang terjadi bisa diselesaikan pula secara tepat.

R. Maisya, N. Hermita, E. Noviana, \& M. Alpusari, Implementasi Metode Outdoor Learning terhadap Complex Problem Solving Skills pada Mata Pelajaran IPA Siswa Kelas v sdn 56 
IImu Pengetahuan Alam (IPA) merupakan pengetahuan tentang fakta dan hukum-hukum yang didasarkan atas pengamatan dan disusun dalam suatu sistem yang teratur. IImu pengetahuan alam juga merupakan suatu ilmu yang mempelajari tentang alam sekitar beserta isinya yakni semua benda yang ada didalam, peristiwa dan gejala-gejala yang muncul di alam. Materi-materi pelajaran IPA memiliki hubungan yang dekat dengan kehidupan sehari-hari, oleh karena itu IPA merupakan salah satu mata pelajaran yang wajib diberikan pada sekolah dasar, yang proses pembelajarannya menekankan pada pemberian pengalaman langsung untuk mengembangkan kompetensi agar peserta didik dapat menjelajahi dan memahami alam sekitar secara sistematis.

Dari permasalahan di atas, maka rumusan masalah dalam penelitian ini adalah: "Apakah terdapat perbedaan complex problem solving skills siswa sebelum dan sesudah diterapkannya metode outdoor learning pada mata pelajaran IPA di kelas V A SDN 56 Pekanbaru?". Tujuan dalam penelitian ini adalah untuk mengetahui perbedaan complex problem solving skills siswa sebelum dan sesudah diterapkannya metode outdoor learning pada mata pelajaran IPA di kelas V SDN 56 Pekanbaru.

\section{METODE PENELITIAN}

Penelitian ini merupakan penelitian dengan menggunakan metode PreExperiment dengan desain penelitian one group pretest posttest design. Penelitian ini dilaksanakan di SDN 56 Pekanbaru yang terletak di Jalan Tengku Cikditiro Waktu penelitian ini dilaksanakan pada semester ganjil pada tahun ajaran 2019/2020 pada bulan September hingga Oktober tahun 2019. Subjek penelitian ini adalah siswa kelas V A SDN 56 Pekanbaru yang berjumlah 19 siswa yang terdiri dari 8 anak lakilaki dan 11 anak perempuan.

Berdasarkan desain diatas dapat dijelaskan bahwa kelas terlebih dahulu diberi pretest sebelum penelitian dimulai. Setelah pembelajaran berlangsung, kelas diberi

R. Maisya, N. Hermita, E. Noviana, \& M. Alpusari, Implementasi Metode Outdoor Learning terhadap Complex Problem Solving Skills pada Mata Pelajaran IPA Siswa Kelas v sdn 56 
perlakuan menggunakan metode outdoor learning. Diakhir proses belajar mengajar, kelas diberi posttest.

Adapun jenis data dalam penelitian ini adalah jenis data kuantitatif. Teknik pengumpulan data dalam penelitian ini dilakukan dengan cara menggunakan lembar yaitu pretest dan posttest siswa berupa soal essay sebanyak 10 soal. Teknik analisis data yang digunakan dalam penelitian ini menggunakan rumus statistik dengan bantuan SPSS dan Microsoft Excel.

\section{HASIL DAN PEMBAHASAN}

Data hasil penelitian yang diperoleh data skor hasil pretest dan posttestcomplex problem solving skills dengan menggunakan metode outdoor learning. Data hasil penelitian didapat sebagai berikut :

Tabel 1. Data Hasil Pretest Posttest

\begin{tabular}{rcccccc}
\hline Data & $\begin{array}{c}\text { Jumlah } \\
\text { Siswa }(\mathrm{n})\end{array}$ & $\begin{array}{c}\text { Rata- } \\
\text { rata }(\bar{x})\end{array}$ & $\begin{array}{c}\text { Standar } \\
\text { Deviasi }(\mathrm{s})\end{array}$ & $\begin{array}{c}\text { Varians } \\
\left(\mathrm{s}^{2}\right)\end{array}$ & $\begin{array}{c}\text { Nilai } \\
\text { Min }\end{array}$ & $\begin{array}{c}\text { Nilai } \\
\text { Max }\end{array}$ \\
\hline Pretest & 19 & 49,05 & 19,66 & 386,52 & 11 & 76 \\
\hline Posttest & 19 & 60 & 17,31 & 299,64 & 16 & 83
\end{tabular}

Dari tabel diatas, dapat diketahui bahwa rata-rata kemampuan awal siswa sebelum perlakuan 49,05, standar deviasi 19,66, varians 386,52, nilai minimum 11 dan nilai maksimum 76. Setelah diberikan perlakuan dapat diketahui bahwa ratarata kemampuan siswa menjadi 60, standar deviasi 17,31, varians 299,64, nilai minimum 16 dan nilai maksimum 83. Maka dari itu dapat dilihat bahwa terdapat perbedaan rata-rata skor pretest dan posttest. Rata-rata hasil tes complex problem solving skills siswa pada pretest sebesar 49,05, sedangkan rata-rata hasil tes complex problem solving skills siswa setelah mendapat perlakuan dengan menggunakan metode outdoor learning kepada siswa mengalami peningkatan yaitu senilai 60. Selisih antara skor pretest dan posttest sebesar 10,95.

\section{Pembahasan}

R. Maisya, N. Hermita, E. Noviana, \& M. Alpusari, Implementasi Metode Outdoor Learning terhadap Complex Problem Solving Skills pada Mata Pelajaran IPA Siswa Kelas v sdn 56 
Hasil penelitian menunjukkan bahwa metode outdoor learning dapat meningkatkan complex problem solving skills siswa kelas V SDN 56 Pekanbaru. Berdasarkan analisis data pada penelitian ini maka dihasilkan beberapa temuan serta pembahasannya diantaranya adalah hasil pretest dan posttest, peningkatan hasil complex problem solving skills siswa kelas V.

Dari data pretest ini dapat disimpulkan hasil complex problem solving skills siswa masih tergolong rendah dan secara umum siswa belum memahami materi. Hal ini disebabkan karena dalam proses pembelajaran guru kurang mengaitkan pembelajaran dengan complex problem solving skills yang dimiliki siswa dan guru lebih dominan melaksanakan pembelajaran secara monoton di dalam kelas sehingga pembelajaran belum optimal.

Setelah melakukan pretest peneliti menggunakan metode outdoor learning untuk meningkatkan complex problem solving skills siswa kelas V A. Penerapan metode outdoor learning ini dilakukan sebanyak dua kali pertemuan. Pada pertemuan pertama siswa mulai tertarik ketika belajar di luar kelas, selanjutnya pertemuan kedua siswa sudah dapat belajar tanpa perlu arahan dari guru, dan siswa sangat antusias serta lebih aktif lagi dalam mengamati lingkungan.

Setelah mengalami proses pembelajaran dengan metode outdoor learning, kemudian peneliti memberikan posttest kepada siswa untuk mengetahui perkembangan pengetahuan siswa setelah menggunakan outdoor learning. Perbedaan hasil dikarenakan ada beberapa kelebihan dari outdoor learning itu sendiri, salah satunya ialah siswa lebih termotivasi dan aktif untuk belajar. Hal ini sesuai dengan pendapat yang telah dikemukakan oleh Husamah (2013) yang menyatakan bahwa metode Outdoor learning dikatakan mampu memberikan pengalaman yang berkesan karena dalam pembelajaran tersebut siswa dapat memaksimalkan penggunaan indra yang mereka miliki demi mengembangkan rasa ingin tahu dan mencapai tujuan pembelajaran yang diinginkan secara langsung di alam terbuka sehingga pembelajaran bersifat konkret serta dapat menyelesaikan berbagai macam permasalahan yang terjadi.

R. Maisya, N. Hermita, E. Noviana, \& M. Alpusari, Implementasi Metode Outdoor Learning terhadap Complex Problem Solving Skills pada Mata Pelajaran IPA Siswa Kelas v sdn 56 
Dari perbedaan rata-rata tes awal dan tes akhir tersebut dapat dilihat bahwa terdapat perbedaan hasil complex problem solving skills siswa antara sebelum menggunakan outdoor learning dan sesudah menggunakan outdoor learning.

\section{SIMPULAN}

Berdasarkan hasil analisis data dan pembahasan, dapat diambil simpulan bahwa terdapat perbedaan complex problem solving skills siswa kelas V A SDN 56 Pekanbaru yang signifikan antara hasil pretest dan hasil posttest menerapkan metode outdoor learning yaitu dari rata-rata tes awal 49,05 menjadi 60 pada tes akhir dengan rata-rata peningkatan 0,21 dengan interpretasi rendah. Hal ini menunjukkan bahwa metode outdoor learning berpengaruh terhadap hasil complex problem solving skills siswa kelas V A SDN 56 Pekanbaru, terlihat pada peningkatan complex problem solving skills siswa yang lebih baik dari pada sebelumnya.

\section{DAFTAR PUSTAKA}

Husamah. 2013. Pembelajaran Luar Kelas Outdoor Learning. Jakarta: Prestasi Pustaka Publisher.

Karmila. 2016. Pengaruh Penerapan Metode Outdoor Learning Berbasis Kelompok terhadap Hasil Belajar IPS di SDN. (02)26-32

Noor, Juliansyah. 2011. Metodologi Penelitian : Skripsi, Tesis, Disertasi, Dan Karya IImiah. Jakarta: Kencana Prenada Media Group.

Siregar, Syofian. 2013. Metode Penelitian Kuantitatif dilengkapi Perbandingan Perhitungan Manual \& SPSS. Jakarta: Kencana Prenada Media Group.

Slameto. 2010. Belajar \& Faktor-faktor yang Mempengaruhinya. Cetakan V. Jakarta: Rineka Cipta.

Sudjana, N \& Rivai, A. 2010. Media Pengajaran. Cetakan IX. Bandung: Sinar Baru Algesindo.

Suprijono. 2010. Cooperative Learning. Cetakan IV. Yogyakarta: Pustaka Pelajar. Suwardana, H. 2017. Revolusi Industri 4.0 Berbasis Revolusi Mental.(01) 102-110.

R. Maisya, N. Hermita, E. Noviana, \& M. Alpusari, Implementasi Metode Outdoor Learning terhadap Complex Problem Solving Skills pada Mata Pelajaran IPA Siswa Kelas v sdn 56 
Vera, Adelia. 2012. Metode Mengajar Anak di Luar Kelas (Outdoor Study). Jogjakarta: DIVA Press.

Widiasworo, Erwin. 2017. Strategi \& Metode Mengajar Siswa di Luar Kelas (Outdoor Learning) secara Aktif, Kreatif, Inspiratif, dan Komunikatif. Yogyakarta: ArRuzz Media.

Widodo Winarso. 2014. Problem Solving, Creativity, dan Decision Making Dalam Pembelajaran Matematika. 03(01):3-4

Yuliarto, H. 2010. Pendidikan Luar Kelas sebagai Pilar Pembentukan Karakter Siswa. Yogyakarta : FIK UNY.

Wahyuni, S. Suana, W. Dkk. 2017. Developing Science Process Skills and Problem Solving Abilities Based On Outdoor Learning In Junior High School. Jurnal Pendidikan IPA Indonesia, (01)165-169. 10.15294/jpii.v6il.6849. 